Open J. Chem., Vol. 1(2018), Issue 1, pp. 36-42

Website: https://pisrt.org/psr-press/journals/ojc/

ISSN: 2618-0758 (online) 2618-074X (Print)

http://dx.doi.org/10.30538/psrp-ojc2018.0005

\title{
SOME ALGEBRAIC POLYNOMIALS AND TOPOLOGICAL INDICES OF MÖBIUS LADDER
}

\author{
MUHAMMAD ASIF TAHIR ${ }^{1}$, SABA NOREEN
}

\begin{abstract}
In this paper we aim to compute some Zagreb type polynomials of Möbius Ladder. Moreover we compute redefined Zagreb indices of Möbius Ladder.

Key words and phrases: Zagreb index; Randić index; Polynomial; Möbius Ladder.
\end{abstract}

\section{Introduction}

The study of topological indices, based on distance in a graph, was effectively employed in 1947 in chemistry by Weiner [1]. He introduced a distance-based topological index called the "Wiener index" to correlate properties of alkenes and the structures of their molecular graphs. These indices play a vital role in computational and theoretical aspects of chemistry in predicting material properties [2, 3-8]. Several algebraic polynomials have useful applications in chemistry, $[9,10]$.

A graph $G$ is an ordered pair $(V, E)$, where $V$ is the set of vertices and $E$ is the set of edges. A path from a vertex $v$ to a vertex $w$ is a sequence of vertices and edges that starts from $v$ and stops at $w$. The number of edges in a path is called the length of that path. A graph is said to be connected if there is a path between any two of its vertices. The distance $d(u, v)$ between two vertices $u, v$ of a connected graph $G$ is the length of a shortest path between them. Graph theory is contributing a lion's share in many areas such as chemistry, physics, pharmacy, as well as in industry [11]. We will start with some preliminary facts.

Received 09-10-2018. Revised 12-11-2018. Accepted 14-11-2018

1 Corresponding Author

(C) 2018 Muhammad Asif Tahir and Saba Noreen. This is an open access article distributed under the Creative Commons Attribution License, which permits unrestricted use, distribution, and reproduction in any medium, provided the original work is properly cited. 
The first and the second Zagreb indices are defined as

$$
\begin{aligned}
& M_{1}(G)=\sum_{u \in V(G)}\left(d_{u}+d_{v}\right), \\
& M_{2}(G)=\sum_{u v \in E(G)} d_{u} \times d_{u},
\end{aligned}
$$

For details see [12]. Considering the Zagreb indices, Fath-Tabar ([13]) defined first and the second Zagreb polynomials as

$$
M_{1}(G, x)=\sum_{u v \in E(G)} x^{d_{u}+d_{v}}
$$

and

$$
M_{2}(G, x)=\sum_{u v \in E(G)} x^{d_{u} \cdot d_{v}}
$$

The properties of $M_{1}(G, x), M_{2}(G, x)$ polynomials for some chemical structures have been studied in the literature $[14,15]$.

After that, in [16], the authors defined the third Zagreb index

$$
M_{3}(G)=\sum_{u v \in E(G)}\left(d_{u}-d_{v}\right)
$$

and the polynomial

$$
M_{3}(G, x)=\sum_{u v \in E(G)} x^{d_{u}-d_{v}} .
$$

In the year 2016, [17] following Zagreb type polynomials were defined

$$
\begin{aligned}
M_{4}(G, x) & =\sum_{u v \in E(G)} x^{d_{u}\left(d_{u}+d_{v}\right)}, \\
M_{5}(G, x) & =\sum_{u v \in E(G)} x^{d_{v}\left(d_{u}+d_{v}\right)}, \\
M_{a, b}(G, x) & =\sum_{u v \in E(G)} x^{a d_{u}+b d_{v}}, \\
M_{a, b}^{\prime}(G, x) & =\sum_{u v \in E(G)} x^{\left(d_{u}+a\right)\left(d_{v}+b\right)} .
\end{aligned}
$$

Ranjini et al. [18] redefines the Zagreb index, i.e, the redefined first, second and third Zagreb indices of graph $G$. These indicators appear as

$$
\begin{aligned}
& R e Z G_{1}(G)=\sum_{u v \in E(G)} \frac{d_{u}+d_{v}}{d_{u} d_{v}}, \\
& \operatorname{Re} Z G_{2}(G)=\sum_{u v \in E(G)} \frac{d_{u} \cdot d_{v}}{d_{u}+d_{v}},
\end{aligned}
$$


and

$$
R e Z G_{3}(G)=\sum_{u v \in E(G)}\left(d_{u}+d_{v}\right)\left(d_{u} \cdot d_{v}\right)
$$

In this paper we compute other Zagreb polynomials and Redefined Zagreb indices of Möbius Ladder. The Möbius ladder $M_{n}$ which is a cubic circulant graph with an even number of vertices, formed from an n-cycle by adding edges (called "rungs") connecting opposite pair of vertices in the cycle. It is so-named because (with the exception of $M_{6}=K_{3,3}$ has exactly $\frac{n}{2}$ 4-cycles which link together by their shared edges to form a topological Möbius strip. Möbius ladders can also be viewed as a prism with one twisted edge. Two different views of Möbius ladders have been shown in Figure 1. Möbius ladders have many applications in chemistry, chemical stereography, electronics and computer science. For our convenience, we view the Möbius ladder $M_{n}$ which is a cubic circulant graph with an even number of vertices, formed from an n-cycle by adding edges (called "rungs") connecting opposite pair of vertices in the cycle.

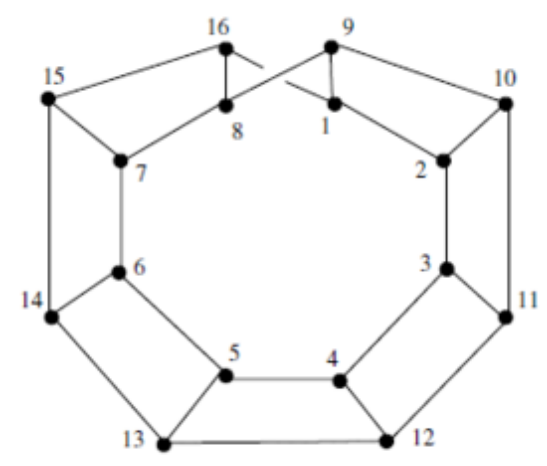

Figure 1. Möbius Ladder $M_{16}$

\section{Computational Results}

Let In this section, we present our computational results.

Theorem 2.1. Let $M_{n}$ be the Möbius Ladder. Then

(1) $M_{3}\left(M_{n}, x\right)=3 n$,

(2) $M_{4}\left(M_{n}, x\right)=3 n x^{18}$,

(3) $M_{5}\left(M_{n}, x\right)=3 n x^{18}$,

(4) $M_{a, b}\left(M_{n}, x\right)=3 n x^{3 a+3 b}$

(5) $M_{M_{n}, b}^{\prime}(G, x)=3 n x^{(3+a)(3+b)}$.

Proof. Let $M_{n}$ be the Möbius Ladder. It is clear that $M_{n}$ has only one partition of vertex set i.e,

$$
V_{1}=\left\{v \in V\left(M_{n}\right): d_{v}=3\right\}
$$

The edge set of $M_{n}$ has following one partition, 


$$
E_{1}=E_{3,3}=\left\{e=u v \in E\left(M_{n}\right): d_{u}=3, d_{v}=3\right\}
$$

Now,

(1)

$$
\left|E_{1}\left(M_{n}\right)\right|=3 n
$$

$$
\begin{aligned}
M_{3}(G, x) & =\sum_{u v \in E\left(M_{n}\right)} x^{\left(d_{u}-d_{v}\right)} \\
& =\sum_{u v \in E_{1}\left(M_{n}\right)} x^{(3-3)} \\
& =\left|E_{1}\left(M_{n}\right)\right| \\
& =3 n .
\end{aligned}
$$

(2)

$$
\begin{aligned}
M_{4}(G, x) & =\sum_{u v \in E\left(M_{n}\right)} x^{d_{u}\left(d_{u}+d_{v}\right)} \\
& =\sum_{u v \in E_{1}\left(M_{n}\right)} x^{3(3+3)} \\
& =\left|E_{1}\left(M_{n}\right)\right| x^{18} \\
& =3 n x^{18} .
\end{aligned}
$$

(3)

$$
\begin{aligned}
M_{5}(G, x) & =\sum_{u v \in E\left(M_{n}\right)} x^{d_{v}\left(d_{u}+d_{v}\right)} \\
& =\sum_{u v \in E_{1}\left(M_{n}\right)} x^{3(3+3)} \\
& =\left|E_{1}\left(M_{n}\right)\right| x^{18} \\
& =3 n x^{18} .
\end{aligned}
$$

(4)

$$
\begin{aligned}
M_{a, b}(G, x) & =\sum_{u v \in E\left(M_{n}\right)} x^{\left(a d_{u}+b d_{v}\right)} \\
& =\sum_{u v \in E_{1}\left(M_{n}\right)} x^{(3 a+3 b)} \\
& =\left|E_{1}\left(M_{n}\right)\right| x^{3 a+3 b} \\
& =3 n x^{3 a+3 b} .
\end{aligned}
$$

(5)

$$
M_{a, b}^{\prime}(G, x)=\sum_{u v \in E\left(M_{n}\right)} x^{\left(d_{u}+a\right)\left(d_{v}+b\right)}
$$




$$
\begin{aligned}
& =\sum_{u v \in E_{1}\left(M_{n}\right)} x^{(3+a)(3+b)} \\
& =\left|E_{1}\left(M_{n}\right)\right| x^{(3+a)(3+b)} \\
& =3 n x^{(3+a)(3+b)} .
\end{aligned}
$$

Theorem 2.2. Let $M_{n}$ be the Möbius Ladder. Then,

(1) $\operatorname{Re} Z G_{1}\left(M_{n}\right)=2 n$,

(2) $\operatorname{Re} Z G_{2}\left(M_{n}\right)=\frac{9}{2} n$,

(3) $\operatorname{Re} Z G_{3}\left(M_{n}\right)=162 n$.

Proof. (1)

$$
\begin{aligned}
\operatorname{Re} Z G_{1}\left(M_{n}\right) & =\sum_{u v \in E\left(M_{n}\right)} \frac{d_{u}+d_{v}}{d_{u} d_{v}} \\
& =\sum_{u v \in E_{1}\left(M_{n}\right)} \frac{d_{u}+d_{v}}{d_{u} d_{v}} \\
& =\sum_{u v \in E_{1}\left(M_{n}\right)} \frac{3+3}{3.3} \\
& =\left|E_{1}\left(M_{n}\right)\right| \frac{6}{9} \\
& =(3 n) \frac{6}{9} \\
& =2 n p .
\end{aligned}
$$

(2)

$$
\begin{aligned}
&{\operatorname{Re} Z G_{2}(G)}=\sum_{u v \in E\left(M_{n}\right)} \frac{d_{u} \cdot d_{v}}{d_{u}+d_{v}} \\
&=\sum_{u v \in E_{1}\left(M_{n}\right)} \frac{d_{u} \cdot d_{v}}{d_{u}+d_{v}} \\
&=\sum_{u v \in E_{1}\left(M_{n}\right)} \frac{3.3}{3+3} \\
&=(3 n) \frac{3}{2} \\
&=\frac{9}{2} n .
\end{aligned}
$$

(3)

$$
R e Z G_{2}(G)=\sum_{u v \in E\left(M_{n}\right)}\left(d_{u} \cdot d_{v}\right)\left(d_{u}+d_{v}\right)
$$




$$
\begin{aligned}
& =\sum_{u v \in E_{1}\left(M_{n}\right)}\left(d_{u} \cdot d_{v}\right)\left(d_{u}+d_{v}\right) \\
& =\sum_{u v \in E_{1}\left(M_{n}\right)}(3.3)(3+3) \\
& =\left|E_{1}(G)\right| 54 \\
& =3 n(54) \\
& =162 n .
\end{aligned}
$$

\section{Competing Interests}

The author do not have any competing interests in the manuscript.

\section{REFERENCES}

1. Wiener, H. (1947). Structural determination of paraffin boiling points. Journal of the American Chemical Society, 69(1), 17-20.

2. Katritzky, A. R., Jain, R., Lomaka, A., Petrukhin, R., Maran, U., \& Karelson, M. (2001). Perspective on the relationship between melting points and chemical structure. Crystal Growth \& Design, 1(4), 261-265.

3. Rücker, G., \& Rücker, C. (1999). On topological indices, boiling points, and cycloalkanes. Journal of chemical information and computer sciences, 39(5), 788-802.

4. Dobrynin, A. A., Entringer, R., \& Gutman, I. (2001). Wiener index of trees: theory and applications. Acta Applicandae Mathematica, 66(3), 211-249.

5. Du, W., Li, X., \& Shi, Y. (2009). Algorithms and extremal problem on Wiener polarity index. MATCH Commun. Math. Comput. Chem, 62(1), 235.

6. Gutman, I., \& Polansky, O. E. (2012). Mathematical concepts in organic chemistry. Springer Science \& Business Media.

7. Ma, J., Shi, Y., \& Yue, J. (2014). The Wiener Polarity Index of Graph Products. Ars Comb., 116, 235-244.

8. Ma, J., Shi, Y., Wang, Z., \& Yue, J. (2016). On Wiener polarity index of bicyclic networks. Scientific reports, 6, 19066.

9. Gutman, I. (1993). Some properties of the Wiener polynomial. Graph Theory Notes New York, 125, 13-18.

10. Deutsch, E., \& Klavžar, S. (2015). M-polynomial and degree-based topological indices. Iran. J. Math. Chem., (6) 93-102.

11. Gutman, I., \& Trinajstić, N. (1972). Graph theory and molecular orbitals. Total $\varphi$-electron energy of alternant hydrocarbons. Chemical Physics Letters, 17(4), 535-538.

12. Fath-Tabar, G. H. (2011). Old and new Zagreb indices of graphs. MATCH Commun. Math. Comput. Chem, 65(1), 79-84.

13. Gutman, I., \& Das, K. C. (2004). The first Zagreb index 30 years after. MATCH Commun. Math. Comput. Chem, 50(1), 83-92.

14. Ranjini, P. S., Lokesha, V., Bindusree, A. R., \& Raju, M. P. (2012). New bounds on Zagreb indices and the Zagreb co-indices. Boletim da Sociedade Paranaense de Matemtica, 31(1), 51-55.

15. Fath-Tabar, G. (2009). Zagreb polynomial and pi indices of some nano structures. Digest Journal of Nanomaterials \& Biostructures (DJNB), 4(1), 189-191.

16. Bindusree, A. R., Cangul, I. N., Lokesha, V., \& Cevik, A. S. (2016). Zagreb polynomials of three graph operators. Filomat, 30(7), 1979-1986. 
17. Ranjini, P. S., Lokesha, V., \& Usha, A. (2013). Relation between phenylene and hexagonal squeeze using harmonic index. International Journal of Graph Theory, 1(4), 116-121.

Muhammad Asif Tahir

Department of Mathematics, The University of Lahore (Pakpattan Campus), Lahore Pakistan.

e-mail: asiftahir46@gmail.com

Saba Noreen

Department of Mathematics and Statistics, The University of Lahore, Lahore Pakistan. e-mail: sabaalvi77@yahoo.com 